\title{
REMOVAL OF BROMATES FROM DRINKING WATER WITH SEVEN TYPES OF SORBENT MATERIALS
}

\author{
${ }^{1}$ Ivana MARKO, ${ }^{2}$ Danka BARLOKOVÁ, ${ }^{3}$ Ján ILAVSKÝ \\ 1,2,3 Department of Sanitary and Environmental Engineering, Faculty of Civil Engineering \\ Slovak Technical University, Radlinského 11, 81005 Bratislava, Slovakia \\ e-mail: ${ }^{1}$ ivana.marko@stuba.sk, ${ }^{2}$ danka.barlokova@stuba.sk, ${ }^{3}$ jan.ilavsky@stuba.sk
}

Received 31 December 2017; accepted 9 May 2018

\begin{abstract}
In analysis of drinking water frequently 'new' elements are occurring, causing a change in water quality. Among these elements bromates are included. Bromates $\left(\mathrm{BrO}_{3}{ }^{-}\right)$are toxic substance that is not commonly determination in drinking water. They are usually formed as byproducts of water disinfection by ozone in the present of bromine ions $\left(\mathrm{BrO}^{-}\right)$in treated water. In some cases, they can be in natural form, for instance in the water source Dvorníky in Slovak Republic. As stated by Environmental Protection Agency bromates are classified as a dangerous substance that can cause health problems and therefore they must be removed from the water.
\end{abstract}

Keywords: Adsorption, Bromates, Drinking water, Removal

\section{Introduction}

Bromates $\left(\mathrm{BrO}_{3}^{-}\right)$are substance that is not common for chemical analysis of drinking water. They can be usually found in mineral or sea water in concentration up to $100.0 \mu \mathrm{g} . \mathrm{L}^{-1}$. Occurrence of bromates in drinking water depends on the presence of bromide ion $\left(\mathrm{BrO}^{-}\right)$in water and water disinfection process by ozone. Under certain conditions, bromates may be formed by oxidation of natural bromine in the presence of oxidizers. They also can be present in concentrated solutions of hypochlorite used for water disinfection [1], [2].

In Slovak Republic the limit value of concentration of bromates in drinking water is $10 \mu \mathrm{g} . \mathrm{L}^{-1}$ [3]. This value is determined by Decree MH SR No. 247/2017 Coll. [3]; and is complied with recommendation of the US Environmental Protection Agency (EPA), World Health Organization (WHO), and Council Directive 98/83/EC [4]. 


\subsection{Effect on human health}

Bromates are toxic substance that in small concentration can cause some health problems, for instance: vomiting, abdominal pain, diarrhea, various degrees of central nervous system depressions, pulmonary edema, and hemolytic-anemia [5]. Majority of these diseases can be cured, but failure of kidneys, and loss of hearing remain as lasting consequences of the usage of a potassium bromate.

The EPA has classified bromates as a possible carcinogen substance, based on the statement of American researches [6]. According to this study, the risk of developing a cancer disease is $10^{-4}$ when a concentration of bromates in water equals $5 \mu \mathrm{g} . \mathrm{L}^{-1}$ [6]. This statement was made by International Agency for Research on Cancer, based on the research which concluded, that long-time exposure of drinking water with a concentration of bromates $5 \mu \mathrm{g} . \mathrm{L}^{-1}$ can cause a human carcinogen. As stated to this argument, the limit concentration of bromates in drinking water in the Europe Union and United States is set to $10 \mu \mathrm{g} . \mathrm{L}^{-1}[6]$.

\subsection{Formatting of bromates during ozonation}

Except for chlorine, ozone is the main oxidizer and disinfectant substance for drinking water treatment. Compared to the other substances, disinfection with ozone can lead to the formatting of by-products in drinking water, and water quality degradation. When water is ozonized it contains bromine ion $\left(\mathrm{BrO}^{-}\right)$, and this leads to formation of bromates $\left(\mathrm{BrO}_{3}^{-}\right)$[6], [7].

The formation of bromates during ozonation is a multistage process, which is influenced by a variety of water quality indicators. These indicators are illustrated in Fig. 1. Oxidation with bromide products reactive bromine, which reacts with the acid and the bases to from hypobromus acid $(\mathrm{HBrO})$ and a bromine ions $(\mathrm{BrO})$. Formation of the $\mathrm{HBrO} / \mathrm{BrO}^{-}$compounds depends primarily on the $\mathrm{pH}$ value of water. The higher value of water $\mathrm{pH}$ (up to 6.0), the more bromine ions $\left(\mathrm{BrO}^{-}\right)$is formed, and vice versa, the lower $\mathrm{pH}$ value of water (lower than 9.5), the more amount of hypobromous acid $(\mathrm{HBrO})$ is formed [8]. The equilibrium between composed $\mathrm{HBrO}$ and $\mathrm{BrO}^{-}$is occurring at $\mathrm{pH}$ value of 8.8 , when these two lines are crossed. In this point the percent composition for each composed is $50 \%$.

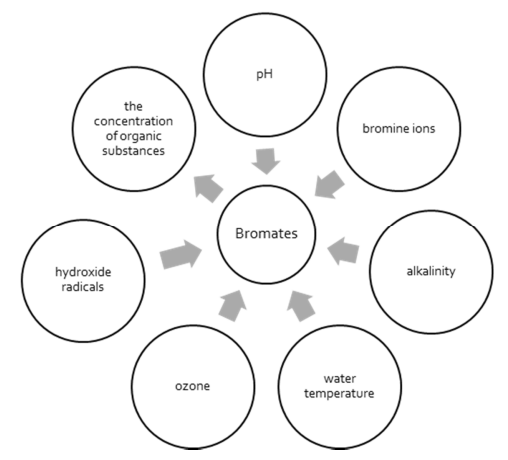

Fig. 1. Water quality indicators that affect the formation of bromates in drinking water 


\section{Methods of bromates removal}

According to the Decree MH SR No. 247/2017 Coll. [3], bromates are qualitative indicators in drinking water that are part of the complete water analysis. Currently there are several methods approved by the EPA, which are applied to determine the concentration of bromates in drinking water. All of the methods are based on the principle of ion chromatography using various detection techniques. The methods are differ from the detection limits, which can be from 0.02 to $1.3 \mu \mathrm{g} . \mathrm{L}^{-1}[1]$.

Currently there are several physical and chemical methods that could be used to remove or reduce concentration of bromates from drinking water. One of the most commonly used method is adsorption with a different type of sorbent material, for instance with the Granulate Activated Carbon (GAC), with efficiency of reduction of bromates about $60 \%$ [6], [9], [10]. Also, there are other methods that are used to remove bromates from drinking water: coagulation with a polyaluminum chloride (removal of bromates 48\%), [11], Ultraviolet (UV) radiation (removal of bromates 16\%) [12] and the highest effect of removing are by the membrane processes. According to the research the effect of bromates removal by reverse osmosis is up to $64 \%$ and by reversal electro-dialysis is $96 \%$ [6].

Recently, a new method for removal of bromates from water has been developed, using adsorption, reduction, and ion-exchange processes [13]. It is essential to note, that efficiency of reducing bromates from drinking water with individual sorbent materials, mainly depends on the chemical composition of water. One of the most important things in choosing the methods of bromates removal from drinking water is knowing the basic characteristics of water source, for instance: water temperature, $\mathrm{pH}$ value, and content of bromine ions, water chemistry, and its changes during seasons, and ozone dosage.

Most commonly used method in water management is adsorption, which ensures the removal of hazardous substances causing changes in water quality: coloring, changed taste and odor properties or substances formed during water disinfection. Application of the adsorption is common for removal of various inorganic and organic substances [1], [14]. Except for the drinking water treatment, adsorption is the most often used process for the remediation of the oil accidents, and the waste water treatment.

\subsection{Sorbent materials used in water treatment}

There are several types of sorbent materials that can be used for water treatment, but most frequently materials are Granulate Active Coal (GAC), Granulated Eisen Hydroxide (GEH), Bayoxide granulated iron hydroxide oxide (CFH) 12 and $\mathrm{CFH} 18$ and other materials with base of iron hydroxide or with layer of $\mathrm{MnO}_{2}, \mathrm{TiO}_{2}, \mathrm{CeO}_{2}$ on their surfaces. Sorbent materials that were studied in this research were chosen according to their high efficiency in removing certain hazardous substances, for instances natural zeolite has presented as suitable material for remove copper and zinc from the water [15], [16], GEH is suitable sorption material for removal of antimony, and arsenic from the water, Bayoxide, and Kemira CFH were developed for removal of arsenic from water [1]. 


\section{Experimental part}

There are natural sources of drinking water that may contain higher concentration of bromates. In Slovakia there is only one known water source, whose concentration of bromates vary during the year from $1.0 \mu \mathrm{g} . \mathrm{L}^{-1}$ up to $40.0 \mu \mathrm{g} . \mathrm{L}^{-1}$ (according to Decree MH SR No. 247/2017 Coll. limit value is $10 \mu \mathrm{g} . \mathrm{L}^{-1}$ ) [3]. This water source is Dvorníky.

In the experiment groundwater from the water source Dvorníky with concentration of bromates $40 \mu \mathrm{g} . \mathrm{L}^{-1}$ was used. Table I illustrates a chemical analysis of raw water from the water source Dvorníky.

\section{Table I}

Chemical analysis of groundwater from the water source Dvorníky

\begin{tabular}{|c|c|c|c|c|c|}
\hline Parameter & Unit & Dvorníky & Parameter & Unit & Dvorníky \\
\hline $\mathrm{pH}$ & & 7.39 & $\mathrm{Ca}^{2+}$ & mg.L.' & 102.0 \\
\hline conductivity & $\mathrm{mS} / \mathrm{m}$ & 65.0 & $\mathrm{Mg}^{2+}$ & $\mathrm{mg} \cdot \mathrm{L}^{-1}$ & 25.84 \\
\hline $\operatorname{TDS}\left(105^{\circ} \mathrm{C}\right)$ & mg. $\mathrm{L}^{-1}$ & 570.0 & $\mathrm{Ca}+\mathrm{Mg}$ & mmol.L $\mathrm{L}^{-1}$ & 3.60 \\
\hline alkality & mmol.L $\mathrm{L}^{-1}$ & 5.71 & $\mathrm{Cl}^{-}$ & $\mathrm{mg} \cdot \mathrm{L}^{-1}$ & 24.35 \\
\hline acidity & mmol. $\mathrm{L}^{-1}$ & 0.55 & $\mathrm{NO}_{3}^{-}$ & $\mathrm{mg} \cdot \mathrm{L}^{-1}$ & 29.21 \\
\hline $\mathrm{COD}-\mathrm{Mn}$ & $\mathrm{mg} \cdot \mathrm{L}^{-1}$ & 0.68 & $\mathrm{SO}_{4}{ }^{2-}$ & $\mathrm{mg} \cdot \mathrm{L}^{-1}$ & 98.46 \\
\hline Fe total & $\mathrm{mg} \cdot \mathrm{L}^{-1}$ & 0.02 & $\mathrm{~F}^{-}$ & $\mathrm{mg} \cdot \mathrm{LL}^{-1}$ & 0.26 \\
\hline $\mathrm{Mn}$ & mg. $L^{-1}$ & 0.024 & $\mathrm{PO}_{4}^{3-}$ & mg.L $\mathrm{L}^{-1}$ & 0.63 \\
\hline
\end{tabular}

Because the input concentration of bromates was too low, to increase the accuracy of measurements in the sample of raw water, standard sodium bromate $\left(\mathrm{NaBrO}_{3}\right)$ was added, which increased concentration of bromates in model water up to the value of $91.3 \mu \mathrm{g} . \mathrm{L}^{-1}$.

During the laboratory tests, the following sorption materials were used:

1. GAC - Filtrasorb F400 (0.42 - 1.68 mm), (Calgon Carbon, Belgium);

2. GEH (0.6 - $1.6 \mathrm{~mm})$, (GEH Wasserchemie, Germany);

3. Bayoxide E33 (0.5 - $2.0 \mathrm{~mm})$, (ferric oxide, Severn Trend, England);

4. Klinopur $\mathrm{Mn}(0.6-1.6 \mathrm{~mm})$, (zeolite with a layer of $\mathrm{MnO}_{2}$ on the surface, Zeocem, a.s.);

5. Read - As (0.3 - $1.0 \mathrm{~mm})$, (ceric oxide, Nihon Kaisui Co Ltd, Japan);

6. Activated alumina $(1.5-2.5 \mathrm{~mm})$, (aluminum oxide, China); and

7. Natural zeolite $(0.5-1.5 \mathrm{~mm})$, Zeocem, a.s. Bystré.

\subsection{Approach of experiment}

The experiment was performed using the batch-test in the laboratory of Slovak Technical University (STU) for eight hours. Into $200 \mathrm{ml}$ of model water with $\mathrm{pH}$ of $7.38,2.0 \mathrm{~g}$ of sorbent materials were added. Together, there were twenty-two samples of which twenty-one with sorbent materials and one sample with raw water. The samples were mixed continuously, and after one hour, four hours, and eight hours was taken out $100 \mathrm{ml}$ of water. After a certain period, model samples were put into dark bottles. In 
order to stabilize bromates, ethylenediamine (EDA) was added $(0.1 \mathrm{ml}$ into $100 \mathrm{ml}$ of the sample). The approach of the laboratory experiment is shown in Fig. 2.

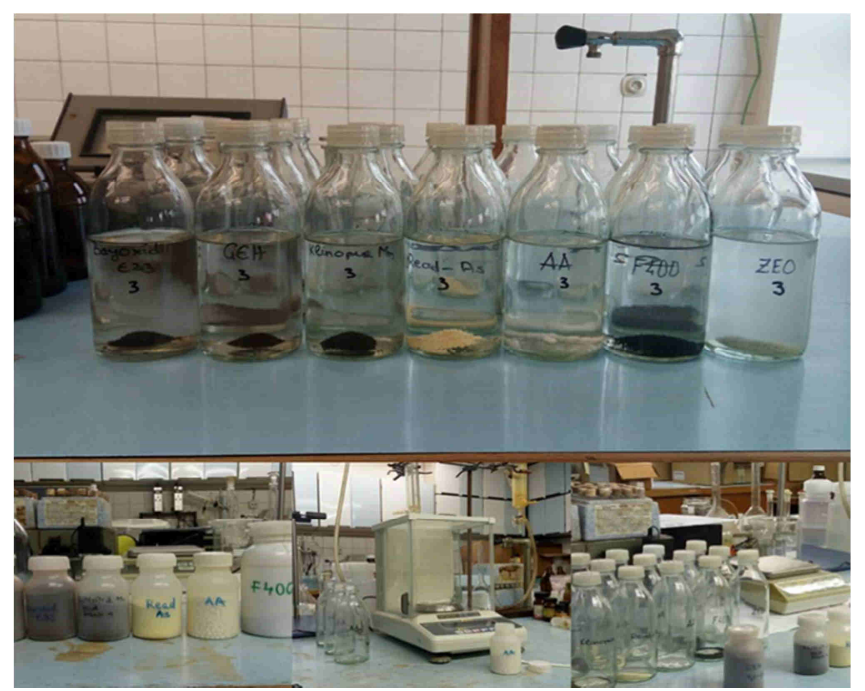

Fig. 2. Approach of experiment in laboratory in STU

The effectiveness of the sorbent materials in removal of bromates from drinking water was monitored by the device EcaFolow 150 GLP made by ISTRAN s.r.o. Slovakia (Fig. 3). These devices functions are based on flow-through coulometer and in-electrode coulometric titrations according to Application List No. 38 [17]. Using this method, bromates in the acid environment are reduced to bromine, which is determined chronopotentiometrically:

$$
\begin{aligned}
& \mathrm{BrO}_{3}^{-}+5 \mathrm{Br}^{-}+6 \mathrm{H}^{+} \rightarrow 3 \mathrm{Br}_{2}+3 \mathrm{H}_{2} \mathrm{O}, \\
& \mathrm{Br}_{2} \rightarrow 2 \mathrm{Br}^{-}+2 \mathrm{e}^{-},[17] .
\end{aligned}
$$

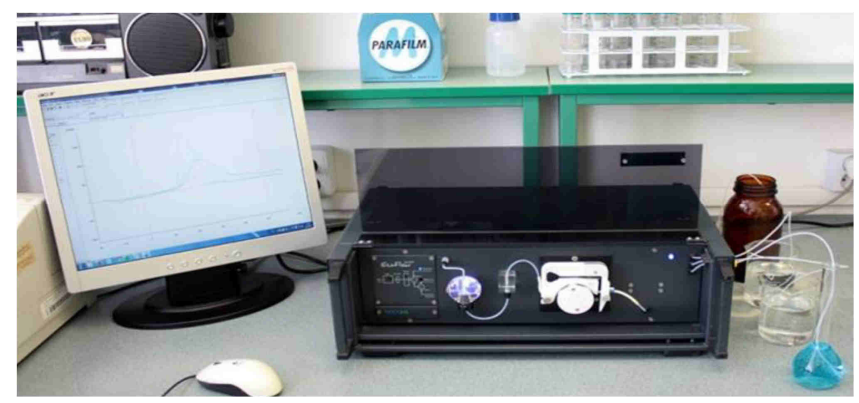

Fig. 3. Device EcaFolow 150 GLP made by ISTRAN s.r.o. Slovakia 
The area of the recognized signal by chronopotentiogram is directly proportional to the concentration of bromates in water. In order to remove distorting impacts of chlorites and other oxidation reagents, $\mathrm{Fe}^{2+}$ is added to the sample [17].

\section{Results and discussion}

The experiment observed the efficiency of the sorbent materials in the removal of bromates from water with $\mathrm{pH}$ value of 7.38 in which the input concentration of bromates was $91.3 \mu \mathrm{g} . \mathrm{L}^{-1}$. The contact of water with sorbent was one hour, four hours and eight hours. Measured values in the batch test were always obtained from two parallel sample measurements. Table II contains the list of results from measuring, that demonstrates a concentration of bromates in particular times for different sorbent materials.

\section{Table II}

Values measured at the experiment

\begin{tabular}{|l|l|c|c|c|c|}
\hline \multirow{2}{*}{ No. } & \multicolumn{1}{|c|}{ Material } & 0 hour & 1 hour & 4 hour & 8 hour \\
\cline { 3 - 6 } & & \multicolumn{4}{|c|}{ Bromates $\left(\mu \mathrm{g} . \mathrm{L}^{-1}\right)$} \\
\hline 1 & Zeolit - SK $(0.5-1.5 \mathrm{~mm})$ & 91.3 & 64.8 & 56.5 & 55.2 \\
2 & Filtrasorb F400 $(0.42-1.68 \mathrm{~mm})$ & 91.3 & 84.6 & 73.1 & 73.0 \\
3 & Akt. Alumina $(1.5-2.5 \mathrm{~mm})$ & 91.3 & 85.5 & 83.7 & 76.4 \\
4 & Read - As $(0.3-1.0 \mathrm{~mm})$ & 91.3 & 87.2 & 72.5 & 63.6 \\
5 & KlinopurMn $(0.6-1.6 \mathrm{~mm})$ & 91.3 & 87.2 & 85.8 & 85.2 \\
6 & GEH $(0.6-1.6 \mathrm{~mm})$ & 91.3 & 79.0 & 75.3 & 66.0 \\
7 & Bayoxide E33 $(0.5-2.0 \mathrm{~mm})$ & 91.3 & 81.3 & 82.3 & 76.1 \\
\hline
\end{tabular}

Based on the defined values the efficiency of bromates removal, $\eta(\%)$ and immediate adsorption capacity of selected sorption materials $a_{t}\left(\mathrm{mg} \cdot \mathrm{g}^{-1}\right)$ were calculated by formula (1) and (2):

$$
\begin{aligned}
& a_{t}=\frac{\left(c_{o}-c_{m}\right) V}{m},\left[\mathrm{mg} \cdot \mathrm{g}^{-1}\right], \\
& \eta=\frac{\left(c_{O}-c_{m}\right) 100}{c_{O}},[\%],
\end{aligned}
$$

where $a_{t}$ is the immediate adsorption capacity $\left(\mathrm{mg}^{-1} \mathrm{~g}^{-1}\right) ; \eta$ is the adsorption efficiency $(\%) ; c_{o}$ is the concentration of bromates before the adsorption $\left(\mu \mathrm{g} . \mathrm{L}^{-1}\right) ; c_{m}$ is the concentration of bromates after the adsorption at the time $\left(\mathrm{mg}^{-\mathrm{L}^{-1}}\right) ; V$ is the volume of water solution $(0.2 \mathrm{~L})$; and $m$ is the weight of sorption material $(2.0 \mathrm{~g})$.

Based on the collected data, graphs were designed for particular parameters for adsorption capacity, concentration of bromates after the adsorption, and adsorption 
efficiency. Results of the data calculation from Table II are shown in Fig. 4, Fig. 5, and Fig. 6.

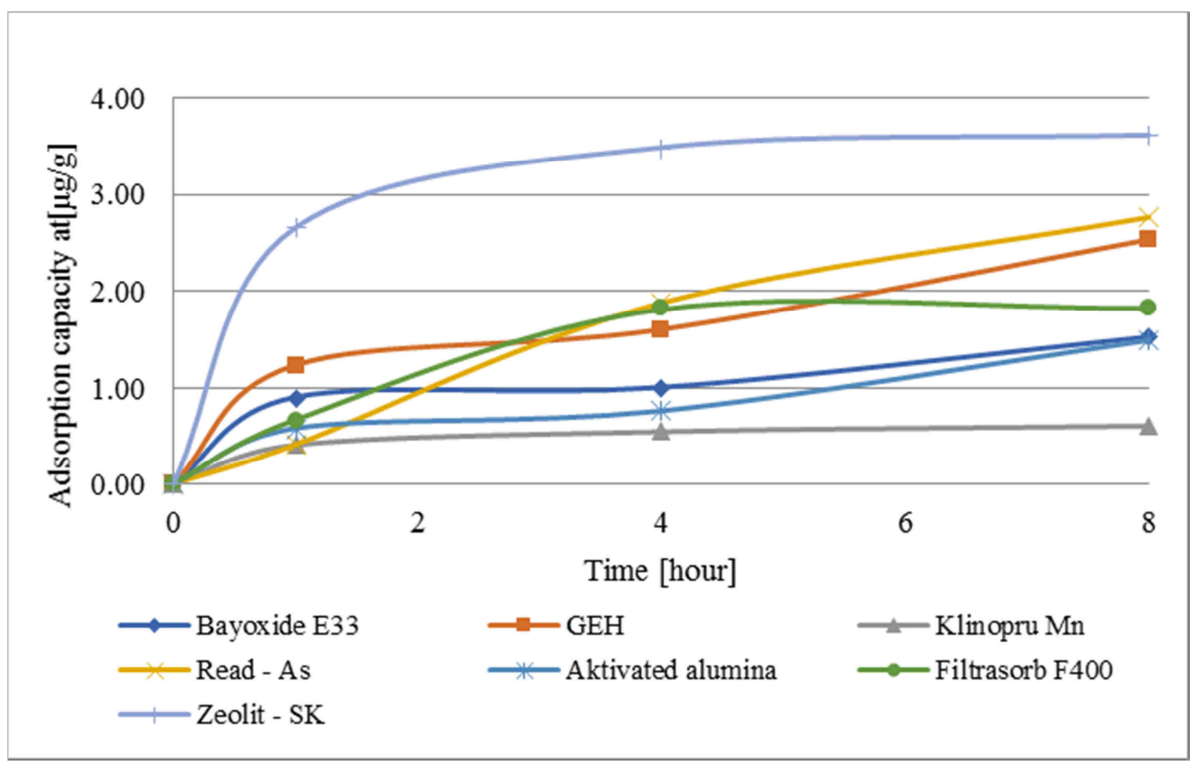

Fig. 4. Course of the adsorbent capacity of bromates removal from drinking water

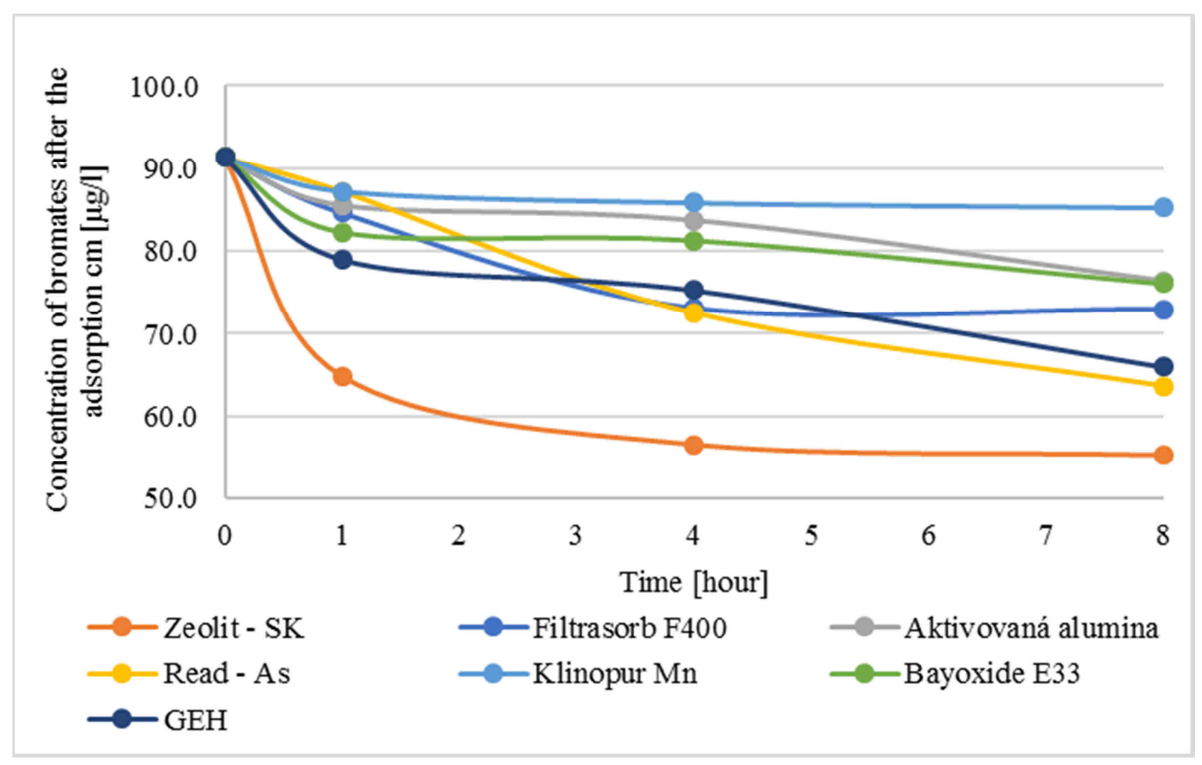

Fig. 5. Course of concentration of bromates after the adsorption at the time 


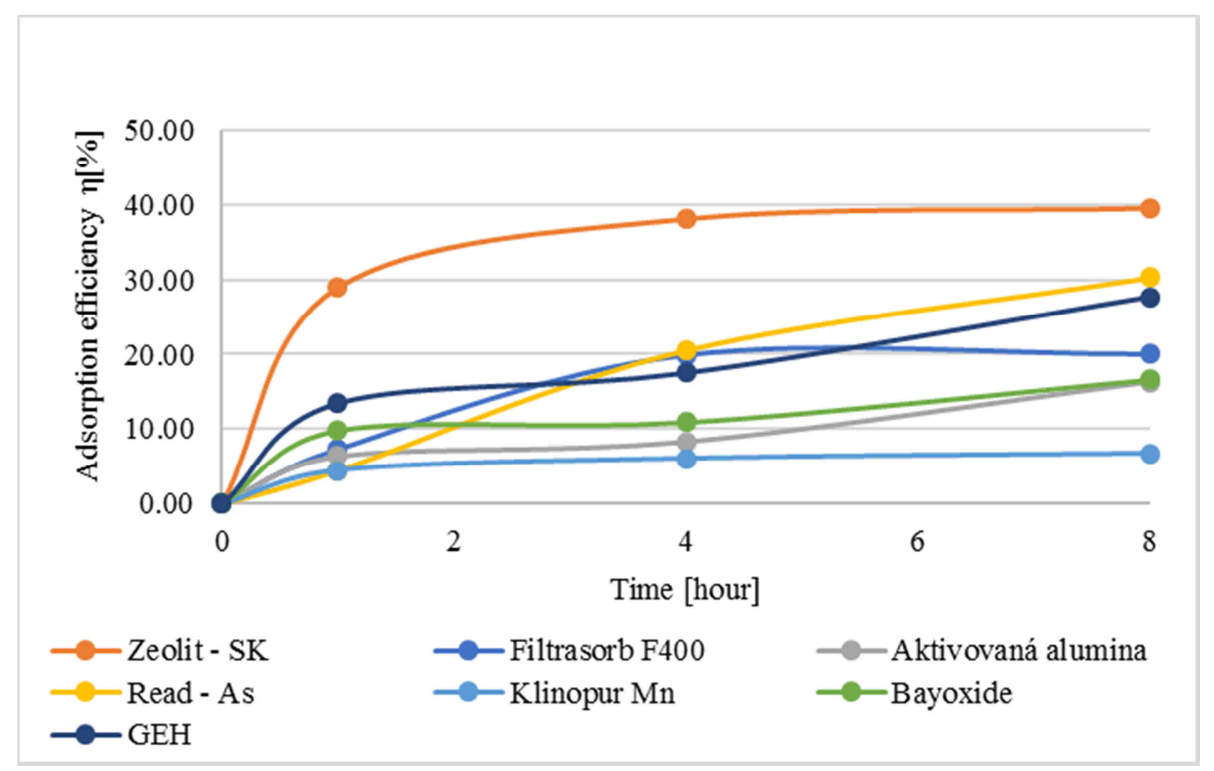

Fig. 6. Course of the adsorbent efficiency of bromates removal from drinking water

The results show that, at $\mathrm{pH} 7.38$ and at the input concentration of bromates before the adsorption $91.3 \mu \mathrm{g} . \mathrm{L}^{-1}$, none of the chosen sorbent materials was able to reduce the concentration of bromates under the limit value determined by MH SR No. 247/2017 Coll [3]. However, the most efficient material was proved to be Zeolite, which was able to remove up to $39 \%$ of bromates after eight hours. The adsorbent capacity of Zeolite varied upon the duration of the contact and increased from $2.55 \mu \mathrm{g} . \mathrm{g}^{-1}$ after the first hour up to $3.61 \mu \mathrm{g} . \mathrm{g}^{-1}$ after eight hours. The efficiency of the other sorbent materials was relatively low, after eight hours they removed less than $30 \%$.

This study was done to find out which sorbent materials is the most suitable for removing of bromates from the drinking water. Based on the results the experiment will be continuing, with focus on a dynamic test where filter columns will be used.

\section{Conclusion}

The purpose of the experiment was to confirm that the reduced concentration of bromates from the water source Dvorníky was not within the determined limits of the Decree MH SR No. 247/2017 Coll. The efficiency of the sorbent material was monitored in the laboratory conditions by the device EcaFolow 150 GLP. The laboratory experiment was conducted in the static test, which determined the adsorption capacity and compared the efficiency of selected sorption materials.

The result of the present study demonstrated that use of Zeolite gave the best results in reducing bromates from the drinking water. In the literature the most suitable sorbent material was the GAC, which can remove up to $60 \%$ of bromates from water. In this research the efficiency of GAC, Filtrasorb F400 after eight hours was only $20.04 \%$ of 
the total amount of the bromates in water. Also, good sorption efficiency was measured for GEH and Read-AS, which have reduced about 30.0\% of bromates after eight hours. To reduce the bromate concentration in the treated water from $91.3 \mu \mathrm{g} . \mathrm{L}^{-1}$ to at least $10.0 \mu \mathrm{g} . \mathrm{L}^{-1}$ the weight of the zeolite must to be $4.5 \mathrm{~g}$.

Experimental research on this topic - removal of bromates from drinking water with sorbent materials will continue with the focus on other prospective materials, sorption on hydraulic conditions, and testing other methods e.g. dynamic test.

\section{Acknowledgements}

This experiment was performed with the financial support of the APVV-15-0379 and VEGA 01/0400/15 projects.

\section{References}

[1] Marko I. Removal of bromates from water, MSc Thesis, Bratislava, Faculty of Civil Engineering, Slovak University of Technology, Bratislava, 2017.

[2] Pitter P. Hydrochemistry, (in Czech) 4th edition, University of Chemistry and Technology in Prague, Czech Republic, 2009.

[3] Decree of the Ministry of Health of the Slovak Republic, No. 247/2017 Coll. laying down details on drinking water quality, drinking water quality control, monitoring and risk management of drinking water supply, (in Slovak), 2017.

[4] Council Directive 98/83/EC of 3 November 1998 on the quality of water intended for human consumption, Official Journal of the European Communities, L 330/32.

[5] WHO 2009 Bromate in drinking-water, background document for development of WHO guidelines for drinking water quality, World Health Organization, Geneva, Switzerland (WHO/SDE/WSH/09.01/6).

[6] Wisniewski J. A., Kabch-Korbutwiz M. Bromate removal in the ion-exchange process, Desalination, Vol. 261, No. 1-2, 2010, pp. 197-201.

[7] von Ganten U., Ozonation of drinking water: part II. disinfection and by-product formation in presence of bromide iodide or chlorine, Water Res, Vol. 37, No. 7, 2003, pp. 1469-1487.

[8] Bromate in drinking water consultation document, by Federal-Provincial-Territorial Committee on Drinking Water Health Canada, 2017, https://www.canada.ca/en/healthcanada/programs/bromate-drinking-water/bromate-drinking-water.html\#purpose, (last visited 8 March 2017).

[9] Huang W. J., Cheng Y. L. Effect of characteristics of activated carbon on removal of bromate, Sep. Purif. Technol. Vol. 59, No. 1, 2008, pp. 101-107.

[10] Chen W. F., Zhang Z. Y., Li Q., Wang H. Y. Adsorption of bromate and competition from oxyanions on cationic surfactant-modified granular activated carbon (GAC), Chemical Engineering Journal, Vol. 203, 1 September 2012, pp. 319-325.

[11] Zhu Q., Liu D. M., Pan Y. H., Wang S. T., Dai C. Y., Han L. M., Cui F. Y., Fang L. Bromate removal by polyaluminum chloride (PAC) coagulation in drinking water, Journal of Harbin Institute of Technology, Vol. 44, 2012, pp. 231-233.

[12] Li W. T., Cao M. J., Young T., Ruffino B., Dodd M., Li A. M., Korshin G. Application of UV absorbance and fluorescence indicators to assess the formation of biodegradable dissolved organic carbon and bromate during ozonation, Water Research, Vol. 111, 2017, pp. $154-162$. 
[13] Kedir A. J., Vohra, M. S. Recent developments in aqueous phase bromate (Bro3 -) species treatment using adsorption, reduction, and ion-exchange processes, Desalination and Water Treatment, Vol. 80, 2017, pp. 255-267.

[14] Malý J., Malá J. Chemistry and water technology, (in Czech) Brno, Czech Republic, Ardec, 2006.

[15] Holub M., Balintova M. Using of zeolite for copper and zinc removal under acidic conditions, Pollack Periodica, Vol. 9, No. 2, 2014, pp. 141-149.

[16] Holub M., Balintova M. Testing of various sorbents for copper sorption from acidic solutions, Pollack Periodica, Vol. 8, No. 2, 2013, pp. 47-54.

[17] Tkáčová J., Horváth M., Kassai A., Kútniková D., Božíková J. Defining bromates by flowthrough coulometry in waters intended for human consumption, Proceedings of Lectures from XIV Conference with International Participation in Drinking Water, Trenčianske Teplice, Slovakia 4-6 October 2011, pp. 315-320. 